\title{
Angiotensin II Type 1 Receptor Blockers Inhibit KAT II Activity in the Brain-Its Possible Clinical Applications
}

\author{
Izabela Zakrocka $^{1}$ - Katarzyna M. Targowska-Duda ${ }^{2}$ - Artur Wnorowski ${ }^{2}$. \\ Tomasz Kocki ${ }^{1}$ - Krzysztof Jóźwiak ${ }^{2}$ • Waldemar A. Turski ${ }^{1}$
}

Received: 14 April 2017 /Revised: 28 June 2017 / Accepted: 5 July 2017 /Published online: 21 July 2017

(C) The Author(s) 2017. This article is an open access publication

\begin{abstract}
Angiotensin II receptor blockers (ARBs) are one of the most frequently recommended antihypertensive drugs. Apart from their activity towards the circulatory system, ARBs also penetrate the blood-brain barrier and display neuroprotective effects. Kynurenic acid (KYNA) is an endogenous metabolite of tryptophan produced by kynurenine aminotransferase II (KAT II) in the brain. Antagonism towards all ionotropic glutamate (GLU) receptors is the main mechanism of KYNA action. An elevated brain level of KYNA is linked with memory impairment and psychotic symptoms. The aim of this study was to examine the influence of three ARBs: irbesartan, losartan, and telmisartan on KYNA production and KAT II activity in rat brain. The effect of ARBs on KYNA production was analyzed in rat brain cortical slices and on isolated KAT II enzyme. Irbesartan, losartan, and telmisartan decreased KYNA production and KAT II activity in a dose-dependent manner in rat brain cortex in vitro. Molecular docking suggested that the examined ARBs could bind to an active site of KAT II. In conclusion, ARBs decrease KYNA production in rat brain by
\end{abstract}

Electronic supplementary material The online version of this article (doi:10.1007/s12640-017-9781-2) contains supplementary material, which is available to authorized users.

Izabela Zakrocka

izabela.zakrocka@umlub.pl

1 Department of Experimental and Clinical Pharmacology, Medical University of Lublin, Jaczewskiego 8b, 20-090 Lublin, Poland

2 Department of Biopharmacy, Medical University of Lublin, Chodźki 4a, 20-093 Lublin, Poland direct inhibition of KAT II enzymatic activity. This novel mechanism of ARBs action may be advantageous in the treatment of cognitive impairment or the management of schizophrenia.

Keywords Kynurenic acid · Renin-angiotensin system • Angiotensin II type 1 receptor blockers · Arterial hypertension $\cdot$ Dementia $\cdot$ Schizophrenia
Abbreviations
ACE Angiotensin converting enzyme
AD Alzheimer's disease
AMPA $\alpha$-Amino-3-hydroxy-5-methyl-4-
isoxazolepropionic acid
ARBs Angiotensin II type 1 receptor blockers
$\mathrm{AT}_{1} \mathrm{R} \quad$ Angiotensin II type 1 receptors
AT-II Angiotensin II
COX-2 Cyclooxygenase-2
DMSO Dimethyl sulfoxide
GLU Glutamate
GPR35 G protein-coupled receptors 35
HPLC High-performance liquid chromatography
KAT Kynurenine aminotransferases
KYN Kynurenine
KYNA Kynurenic acid
NMDA $N$-methyl-D-aspartate
PMP 4'-Deoxy-4'-aminopyridoxal-5'-phosphate
RAS Renin-angiotensin system
RVLM Rostral ventrolateral medulla
SHR Spontaneously hypertensive rats
SPR Stroke-prone spontaneously hypertensive rats 


\section{Introduction}

Arterial hypertension remains the most common cardiovascular disorder affecting nearly half of the population (ESH/ESC Task Force for the Management of Arterial Hypertension 2013). The prevalence of hypertension is closely related with the occurrence of stroke, myocardial infarction, kidney failure, and higher mortality risk (Mankin 2016). Despite a variety of antihypertensive drugs being available, an appropriate blood pressure control is still difficult to achieve in a large group of patients with arterial hypertension (Sarganas and Neuhauser 2016). According to the guidelines, renin-angiotensin system (RAS) inhibitors are the most preferred hypotensive agents. With the exception of a decrease in blood pressure, their antiinflammatory and antioxidative properties are responsible for end-organ protection and mortality reduction (MuñozDurango et al. 2016).

Studies on RAS revealed the occurrence of tissue RAS and its paracrine function (Baltatu et al. 2011). The presence of RAS in the brain began to attract the attention of neuroscientists. First information about renin-like enzyme forming angiotensin in the brain was published by Ganten et al. (1971). Apart from its role in water and electrolyte homeostasis, brain RAS is linked with the development of epilepsy (Pereira et al. 2010), Alzheimer's disease (AD) (Hajjar and Rodgers 2013), Parkinson's disease (Labandeira-García et al. 2014), and neuropathic pain (Muthuraman and Kaur 2016). Active components of RAS are synthesized from angiotensinogen present primarily in glial cells (Intebi et al. 1990). The main receptors responsible for angiotensin II (AT-II) action are AT-II type 1 receptors $\left(\mathrm{AT}_{1} \mathrm{R}\right)$ which dominate in astroglial cells (Sumners et al. 1994). Activation of central $\mathrm{AT}_{1} \mathrm{R}$ by AT-II is linked with the pathogenesis of hypertension (Toney and Porter 1993). Reduction of AT-II synthesis and inhibition of $\mathrm{AT}_{1} \mathrm{R}$ are the main goals of antihypertensive therapy. Since other enzymes, e.g., tonin, may produce AT-II from angiotensin I or angiotensinogen (Kondo et al. 1980), $\mathrm{AT}_{1} \mathrm{R}$ blockers (ARBs) seem to provide better control over RAS activity than angiotensin converting enzyme (ACE) inhibitors.

Kynurenic acid (KYNA), an endogenous metabolite of tryptophan, was discovered in the nineteenth century in the dogs' urine by Justus von Liebig (1853). In the brain, KYNA production from precursor kynurenine (KYN) takes place mainly in astrocytes (Guillemin et al. 2000). Among kynurenine aminotransferases (KAT) catalyzing KYNA synthesis, KAT II has a dominant role in this process (Nematollahi et al. 2016). It is well established that the main mechanism of KYNA action is the blockade of ionotropic glutamate (GLU) receptors, $N$-methyl-D-aspartate (NMDA), $\alpha$-amino-3-hydroxy-5-methyl-4-isoxazolepropionic acid (AMPA), and kainate (Schwarcz and Stone 2017). Noncompetitive antagonism towards the $\alpha 7$ nicotinic acetylcholine receptors (Beggiato et al. 2013) or activation of G protein- coupled receptors 35 (GPR35) (Stone et al. 2013) are other effects of KYNA. GLU injected into the rostral ventrolateral medulla (RVLM) was shown to elevate blood pressure and heart rate in anesthetized rats (Willette et al. 1987). KYNA, as a GLU antagonist, was proven to lower blood pressure after central administration (Araujo et al. 1999; Ito et al. 2000).

Considering that ARBs have been shown to abolish central pressor GLU effect (Vieira et al. 2010), the goal of the present study was to examine the influence of three ARBs, irbesartan, losartan, and telmisartan, on KYNA synthesis and KAT II activity in rat brain cortex in vitro. In addition, the available crystal structure of the human KAT II (hKAT II) in complex with its substrate KYN and 4'-deoxy-4'-aminopyridoxal-5'phosphate (PMP) enabled us to predict a possible binding site for the studied ARBs.

\section{Materials and Methods}

\section{Animals}

Experiments were performed on male Wistar rats (weight 150-200 g) obtained from an accredited breeder (Brwinów, Poland). Animals were kept under standard laboratory conditions at room temperature, 12-h light-dark cycles, and in cages with food and water available ad libitum. Procedures were conducted between 7 a.m. and 1 p.m. All animals were adapted to laboratory conditions for 7 days before tests were carried out. Procedures were accepted by the I Local Ethics Committee for Animal Experiments in Lublin and are in agreement with Directive 2010/63/EU on the protection of animals used for scientific purposes.

\section{Chemical Substances}

The following chemicals were purchased from SigmaAldrich: L-kynurenine (sulfate salt), irbesartan, losartan potassium, telmisartan, dimethyl sulfoxide (DMSO), sodium chloride, potassium chloride, magnesium sulfate, calcium chloride, sodium phosphate monobasic, sodium phosphate dibasic, glucose, distilled water, Trizma base, acetic acid, pyridoxal 5'-phosphate, 2-mercaptoethanol, pyruvate, and glutamine. Substances of the highest purity used for high-performance liquid chromatography (HPLC) were obtained from J. T. Baker Chemicals and Sigma-Aldrich.

\section{Experiments Conducted on Cortical Slices}

Experiments on cortical slices were performed as previously described by Turski et al. (1989). After the rats' decapitation, their brains were removed from the skulls and placed on ice. Brain cortex was immediately separated from the white matter and cut with a Mcllwain tissue chopper (Mickle Laboratory 
Engineering Co. Ltd., USA). Cortical slices (size $1 \mathrm{~mm} \times 1 \mathrm{~mm}$ ) were placed into incubation wells (10 slices in each well), filled with $1 \mathrm{ml}$ of oxygenated Krebs-Ringer buffer at $\mathrm{pH}$ 7.4. The incubation lasted $2 \mathrm{~h}$ at $37^{\circ} \mathrm{C}$ in the presence of $10 \mu \mathrm{M}$ L-KYN and one of four drug concentrations $(0.01$, $0.05,0.1$, or $1 \mathrm{mM}$ ). Minimum six wells were used to examine each drug concentration. The incubation was ended by placing the samples into an ice-cold bath. Obtained supernatants were centrifuged $(15,133 \times \mathrm{g}$ for $15 \mathrm{~min})$ and applied to ion exchange resin Dowex $50 \mathrm{~W}+$ column. Eluted KYNA was separated by the HPLC (Thermo Fisher Scientific HPLC system, ESA catecholamine HR-80, $3 \mu \mathrm{m}, \mathrm{C} 18$ reverse-phase column) and quantified fluorometrically. The resulting peak was compared with the authentic KYNA. Experiments were conducted at least three times to achieve comparable results.

\section{Evaluation of Kynurenine Aminotransferase Activity}

Analysis of KAT II activity was performed according to the method by Guidetti et al. (1997). To examine KAT II activity, the brain cortex was homogenized in dialysate buffer made from $5 \mathrm{mM}$ Tris-acetate buffer at $\mathrm{pH}$ 8.0, $50 \mu \mathrm{M}$ pyridoxal 5'phosphate, $10 \mathrm{mM}$ 2-mercaptoethanol, and distilled water. Prepared homogenate was centrifuged $(15,133 \times \mathrm{g}$ for $15 \mathrm{~min}$ ) and the supernatant dialyzed for $12 \mathrm{~h}$ at $8{ }^{\circ} \mathrm{C}$ using cellulose membrane dialysis tubing (dialysis tubing cellulose membrane, average flat width $10 \mathrm{~mm}$; Sigma-Aldrich) in 41 of the dialysate buffer. Afterwards, the enzyme preparation was incubated in the reaction mixture containing incubation solution, $2 \mu \mathrm{M}$ L-KYN, and solutions of tested drugs (at 0.01, 0.05 0.1 , and $1 \mathrm{mM}$ concentration). The reaction $\mathrm{pH}$ was 7.0 (optimal $\mathrm{pH}$ for KAT II). L-glutamine was added to inhibit KAT I activity. Three probes were used for each drug concentration. The incubation lasted for $2 \mathrm{~h}$ at $37^{\circ} \mathrm{C}$ and was ended by transferring the samples to an ice-cold bath. Supernatants were centrifuged and KYNA content analyzed, as described previously.

\section{Statistical Analysis}

Data were presented as a percentage of control values. Mean and standard error of the mean (SEM) were calculated. Statistical analysis was performed using one-way analysis of variance (ANOVA) with a post hoc Tukey-Kramer test. $P<0.05$ was considered statistically significant. All calculations were made with the GraphPad InStat program, version 3.06 .

\section{Molecular Docking of ARBs and Kynurenine to KAT II}

The available crystal structure of the hKAT II in complex with its substrate kynurenine and co-factor PMP at $1.95 \AA$ atomic resolution (PDB ID: 2R2N) (Han et al. 2008) was used to perform the molecular docking. More specifically, each studied ligand (i.e., irbesartan, losartan, and telmisartan) (Molfile) was imported from the ChEMBL Database and optimized using the semi-empirical method AM1, and then transferred for the subsequent step of ligand docking. Molegro Virtual Docker (v 6.0.0, Molegro ApS, Aarhus, Denmark) was used for docking simulations of flexible ligands into the rigid KAT II target. The docking space (a sphere of $20 \AA$ diameter) was defined to cover KYN (substrate), and the co-factor (PMP). KYN was then removed and each ARB was docked to the KAT II structure. The actual docking simulations were performed using the following settings: number of runs $=100$, maximal number of poses returned $=10$. Additional docking was performed for KYN to check the correctness of the docking procedure. The lower energy conformations were selected from each cluster of superposed poses for each studied ligand.

\section{Results}

\section{Evaluation of KYNA Production in Brain Cortical Slices In Vitro}

De novo production of KYNA in rat brain slices in vitro under standard conditions was $3.41 \pm 0.07 \mathrm{pmol} /$ well. All analyzed ARBs, irbesartan, losartan, and telmisartan decreased KYNA production in rat brain cortical slices in vitro (Fig. 1). At the concentration of 0.5 and $1 \mathrm{mM}$ irbesartan decreased KYNA production to $66 \%(P<0.001)$ and $42 \%(P<0.001)$ of the control value, respectively (Fig. 1a). Losartan at the concentration of 0.5 and $1 \mathrm{mM}$ inhibited KYNA synthesis to $51 \%$ $(P<0.001)$ and 37\% $(P<0.001)$ of the control value, respectively (Fig. 1b). Telmisartan at 0.1 and $0.5 \mathrm{mM}$ concentration decreased KYNA production to $62 \%(P<0.001)$ and $57 \%$ $(P<0.001)$ of the control value, respectively (Fig. 1c).

\section{Evaluation of KAT II Activity in Brain Cortical Homogenates In Vitro}

The mean activity of KAT II under standard conditions was $19.17 \pm 1.15$ pmol of KYNA per test tube. Irbesartan at 0.5 and $1 \mathrm{mM}$ concentration inhibited KAT II in rat brain cortical homogenates in vitro to $45 \%(P<0.001)$ and $25 \%(P<0.001)$ of the control value, respectively (Fig. 2a). Losartan decreased KAT II activity in rat brain cortical homogenates in vitro at the concentration of $0.01,0.1,0.5$, and $1 \mathrm{mM}$ to $59 \%(P<0.001)$, $10 \%(P<0.001), 6 \%(P<0.001)$, and $1 \%(P<0.001)$ of the control value, respectively (Fig. 2b). Telmisartan at 0.1 and $0.5 \mathrm{mM}$ concentration decreased KAT II activity in rat brain cortical homogenates in vitro to $63 \%(P<0.05)$ and $32 \%$ $(P<0.01)$ of the control value, respectively (Fig. 2c). 

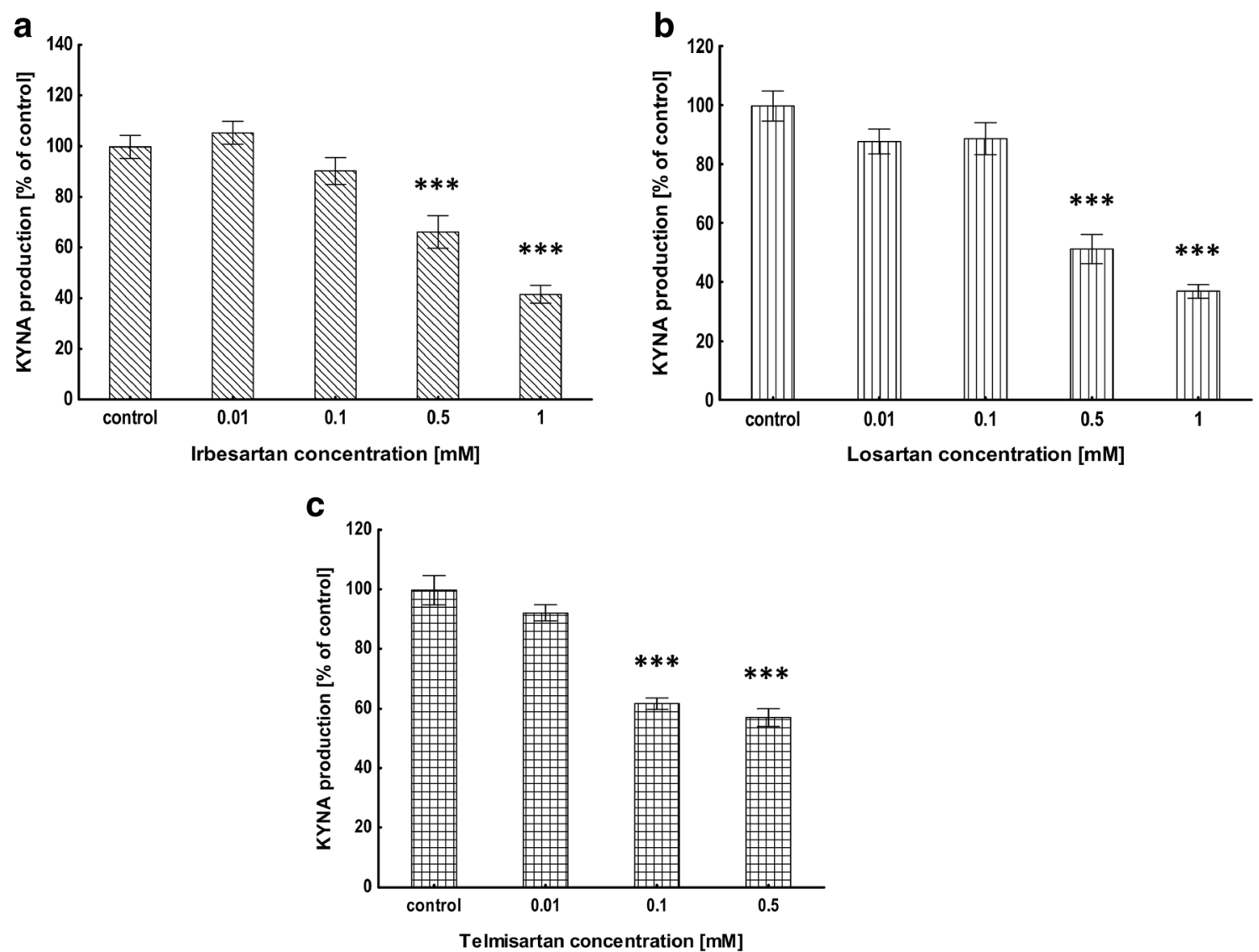

Fig. 1 Influence of irbesartan (a), losartan (b) and telmisartan (c) on KYNA production in rat brain cortical slices in vitro. Data are expressed as a percentage of the control production, mean $\pm \mathrm{SEM}$,

\section{Molecular Docking of ARBs and Kynurenine to KAT II}

The molecular docking results showed that each studied ARB (structures presented in Fig. 3) binds to the KAT II active site. In addition, our results suggested a similar KYN orientation within the KAT II active site as determined in the threedimensional crystal structure (Han et al. 2008) of KAT II with KYN (PDB ID: 2R2N). This confirmed the correctness of the docking procedure. Our findings suggest two orientations of losartan and irbesartan at the enzyme active site, and one proposal for telmisartan (Fig. 4 and Table S1). More specifically, in both orientations, losartan interacts with the residues indicated for KYN, including Ile19 (A), Arg20 (A), Gly39 (A), Leu40 (A), Tyr74 (A), Leu293 (A) from one subunit, and Tyr142 (B), Ser143 (B), Asn202 (B), Tyr233 (B), Phe355 (B), Phe387 (B), and Arg399 (B) from the opposite subunit. In addition, this molecule interacts with additional residues (mostly the same for both orientations). In orientation 1 , the hydrogen bond interactions suggested by the docking are formed between the tetrazole moiety of losartan and Asn202 (B) Ser143 (B), and Arg399 (B); between losartan imidazole moiety and Ser17 (A), Arg20 (A), Ser77 (A), and Leu293 (A); as well as between losartan and water molecule (Fig. 4a and $n=6$, ANOVA with post hoc Tukey-Kramer test, and triple asterisks indicate $P<0.001$ vs. control

Table S1). In orientation 2, tetrazole moiety is oriented in the opposite direction compared to orientation 1. More specifically, the hydrogen bonds are formed between tetrazole moiety of losartan and Ser17 (A), Thr142 (B), and Ser143, and between losartan imidazole moiety and Asn202 (B), Gly39 (A), Pro41 (A), and Tyr233 (B), as well as between losartan and water molecule (Fig. 4b). In orientation 2, two additional hydrogen bonds are suggested between losartan and PMP (co-factor) bound to the KAT II active site (Fig. 4b and Table S1).

Results of the molecular docking indicate almost the same orientations of irbesartan (Figs. 3 and 4c) within KAT II active site as described for losartan (Figs. 3 and 4a). In orientation 1, the same residues are shown for irbesartan as for losartan binding, whereas a reduced number of hydrogen bonds are suggested. In particular, the hydrogen bonds are formed between tetrazole moiety of irbesartan and Asn202 (B) and Arg399 (B); between irbesartan imidazole moiety and $\operatorname{Ser} 17$ (A), Ser77 (A), and Arg20 (A); as well as between irbesartan and water molecule (Fig. 4c and Table S1). Although two additional hydrogen bonds are suggested between irbesartan (in orientation 2) and PMP (cofactor) (Fig. 4d and Table S1), the reduced number of hydrogen bonds [i.e., one between tetrazole moiety of the ligand and Arg20 (A), and between ligand imidazole moiety and Arg399 (B) and 

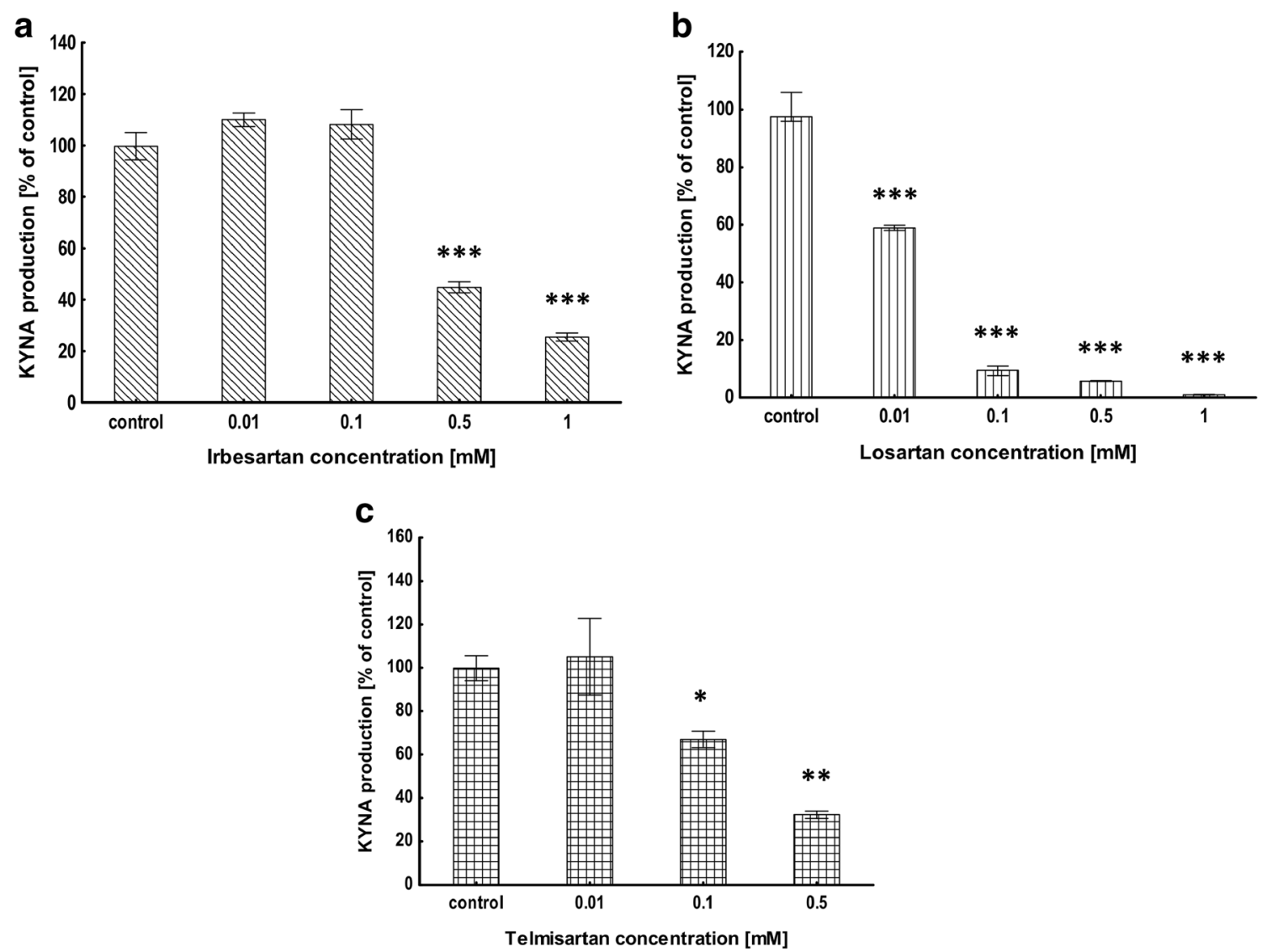

Fig. 2 Influence of irbesartan (a), losartan (b) and telmisartan (c) on KAT II activity in rat brain cortex in vitro. Data are expressed as a percentage of the control KYNA production, mean $\pm \mathrm{SEM}, n=3$, ANOVA with post

hoc Tukey-Kramer test, and single asterisk indicates $P<0.05$ vs. control, double asterisks indicate $P<0.01$ vs. control, and triple asterisks indicate $P<0.001$ vs. control

Asn202 (B) (Fig. 4d)] is suggested for irbesartan bound to the KAT II active site.

Finally, the molecular docking data suggest that telmisartan binds to the same site as previously indicated for losartan and irbesartan at the KAT II active site. However, there are few more residues not involved in losartan and irbesartan binding. In addition, a lower number of hydrogen bonds is suggested, including that formed between the ligand and Pro16, Ser17, Ser143, and Arg399 (Fig. 4e and Table S1).

\section{Discussion}

The present study shows that all examined ARBs, irbesartan, losartan, and telmisartan, reduce KYNA production in brain cortical slices in vitro. Moreover, all analyzed ARBs decrease the activity of KAT II in brain cortical homogenates in vitro. KAT II is a crucial enzyme involved in KYNA synthesis that uses KYN as a substrate. The crystal structure of the native complex of KAT II with KYN (Han et al. 2008) provided an important molecular basis for a comprehensive understanding of the substrate binding and catalysis in KAT II, thus enabling us to study the possible binding of ARBs (i.e., irbesartan, losartan, and telmisartan) to this enzyme. Docking simulations suggest that all studied ARBs bind to the KAT II active site. In addition, all ligands interact mostly with the same amino acids, including residues indicated for the KYN complex with KAT II (PDB ID: 2R2N). Finally, a higher number of hydrogen bonds are suggested for losartan, the compound experimentally determined to be the most potent inhibitor among tested ARBs.

Most studies on the pathogenesis of arterial hypertension have focused primarily on the peripheral mechanisms of blood pressure regulation, with lesser interest on the central nervous system. Among known pressor agents, AT-II and GLU play pivotal roles in the brain centers involved in blood pressure control in both normotensive and spontaneously hypertensive rats (SHR) (Muratani et al. 1991). Moreover, the location of $\mathrm{AT}_{1} \mathrm{R}$ in the central nervous system is strongly related to the cardiovascular regulation centers (Tagawa et al. 2000). The link between brain angiotensinergic and glutamatergic signaling was presented by Vieira et al. (2010). The major sympathetic output pathway for the tonic and reflex control of blood pressure, which uses GLU as the transmitter, arises from the rostral ventrolateral medulla (RVLM) (Colombari et al. 2001). Injection of AT-II into the RVLM of unanesthesized rats was shown to exaggerate pressor response to GLU. Administration 
Fig. 3 Molecular structures of ARBs (i.e., irbesartan, losartan, and telmisartan) and KYN (physiological KAT II substrate)<smiles>CCCCC1=NC2(CCCC2)C(=O)N1Cc1ccc(-c2ccccc2-c2nn[nH]n2)cc1</smiles>

Irbesartan

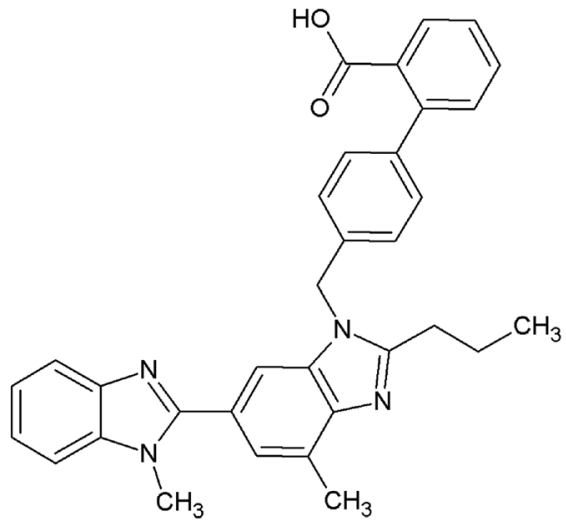

Telmisartan<smiles>CCCCC1=NC(Cl)C(CO)N1Cc1ccc(-c2ccccc2-c2nn[nH]n2)cc1</smiles>

Losartan<smiles>Nc1ccccc1C(=O)CC(N)C(=O)O</smiles>

Kynurenine of losartan into the RVLM reduced an increase in blood pressure caused by both GLU and AT-II (Vieira et al. 2010). Additionally, it is speculated that AT-II takes part in GLU pressor responses by presynaptic increase of GLU input into the RVLM (Kumagai et al. 2012).

Referring to this, KYNA (GLU antagonist) is claimed to be a hypotensive agent. Mills et al. (1990) reported that intrathecal KYNA administration decreased blood pressure, especially in anesthetized SHR and stroke-prone spontaneously hypertensive rats (SPR), with less noticeable effect in normotensive rats. What is more, lower KYNA content and decreased brain KAT activity in SHRs were observed (Kapoor et al. 1994). Ito et al. (2000) showed that KYNA injected into the RVLM of anesthetized SHR effectively reduced mean arterial pressure. The role of KYNA in blood pressure control was further emphasized by the discovery of a missense KAT I mutation E61G, which accounts for the reduced activity of KAT I as well as decrease in KYNA production in SHR (Kwok et al. 2002). Additionally, Mizutani et al. (2002) presented in SHR brainstem a higher expression of kynureninase, another enzyme involved in $\mathrm{KYN}$ degradation. Since the increased expression of kynureninase in SHR is thought to decrease the KYN level (Mizutani et al. 2002) and KYN is a precursor of KYNA, a decreased KYNA level can be expected in hypertensive rats. Interestingly, both an increase of mean arterial pressure and of splanchnic sympathetic nerve activity, evoked by AT-II administration into RVLM, were reduced by local administration of candesartan as well as KYNA (Kido et al. 2004). Considering the hypotensive activity of KYNA in the brain, the fact that all tested ARBs decreased the synthesis of this GLU antagonist is unexpected.

If ARBs decrease KYNA content in the brain and KYNA exerts neuroprotective and anticonvulsant activity (Schwarcz et al. 1987), an intensification of neurodegenerative processes and proconvulsant action of ARBs should be expected. To the contrary, ARBs are reported to be neuroprotective and anticonvulsant. Telmisartan, candesartan, losartan, and valsartan significantly reduced GLU-induced neuronal injury and apoptosis in cultured rat primary cerebellar granule cells (Wang et al. 2014). Losartan prevented neuronal loss and inhibited cognitive impairment in the pilocarpine-induced status epilepticus in rats (Sun et al. 2015) and exerted neuroprotection in the CA1 area of the hippocampus in the kainate model of temporal lobe epilepsy in rats (Tchekalarova et al. 2014). Moreover, losartan decreased seizure severity in Wistar audiogenic rats (Pereira et al. 2010) and prevented the development of delayed recurrent spontaneous seizures in two rat models of vascular injury (Bar-Klein et al. 2014).

In opposition to this, an elevated content of KYNA was linked with AD occurrence. Baran et al. (1999) reported significant KYNA increase in the putamen and caudate nucleus 

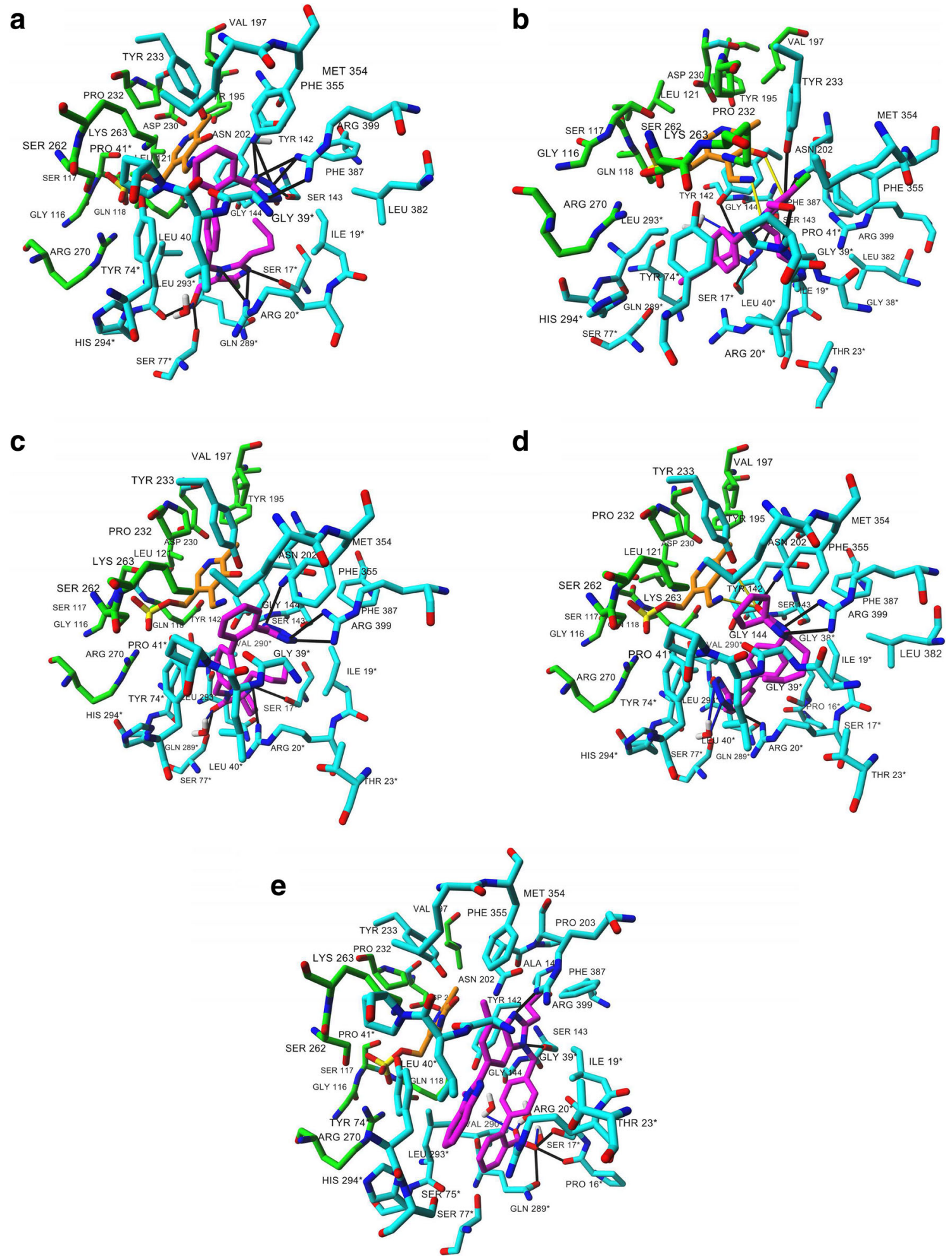

Fig. 4 Molecular docking of losartan, irbesartan, and telmisartan to the crystal structure of KAT II (PDB ID: 2R2N). All ligand binding sites overlap the KYN binding pocket. Two different ligand orientations are suggested for losartan $(\mathbf{a}, \mathbf{b})$ and irbesartan $(\mathbf{c}, \mathbf{d})$, and one for telmisartan (e). Ligand and co-factor are rendered in stick mode; residues involved in each ligand and PMP binding are shown in cyan and green, respectively. Residues from chain A are labeled with an asterisk to differentiate chain A from chain B residues. Black solid lines indicate hydrogen bonds as

well as salt bridges formed between each ligand and amino acid residues, blue solid lines between ligands and water molecules, and yellow solid lines indicate the hydrogen bonds formed between losartan (b) or irbesartan (d) and the co-factor. All residues involved in hydrogen bonding are marked in red. Oxygen atoms are colored red, nitrogens blue, phosphorus yellow, and chlorine green. All hydrogen atoms are hidden (color figure online) 
of AD brain, compared to other brain regions. In addition, this elevated KYNA level correlated with a significant increase in KAT I activity in both nuclei (Baran et al. 1999). Malkova et al. (2015) showed that intracerebral KYNA infusion impaired object recognition memory in macaques. Importantly, reduction of brain KYNA by PF-04859989, a brainpenetrable inhibitor of KAT II, improved cognitive function in rodents and nonhuman primates (Kozak et al. 2014).

In this study, ARBs inhibited KAT II activity and reduced the production of KYNA in rat cortical slices. According to the hypothesis that KYNA produces cognitive impairment, it can be expected that ARBs would positively affect the memory processes. Indeed, losartan improved cerebrovascular function in a mouse model of $A D$ (Papadopoulos et al. 2017). Danielyan et al. (2010) have proved in a transgenic mouse model of AD that losartan given intranasally exerts a neuroprotective effect in concentrations much lower than that needed to decrease blood pressure. Moreover, enhancing memory effects were observed in humans treated with ARBs. Losartan improved cognitive function, mainly immediate and delayed memory in elderly hypertensive humans (Fogari et al. 2003) and in healthy young adults (Mechaeil et al. 2011). Accumulated data unequivocally indicate the beneficial effect of ARBs in memory impairment. However, the mechanism of such ARBs' action is unknown. Our results imply that the decrease in KYNA production by ARBs may be responsible for the improving effect of these drugs on cognition.

Apart from memory improvement, ARBs may be beneficial in the treatment of psychotic disorders by decreasing KYNA production. High KYNA content, especially in the central nervous system, has been reported in patients with schizophrenia (Plitman et al. 2017). The reason for such an observation is unknown. One of the possible explanations is the involvement of RAS. It has been shown that RAS hyperactivity results in the alteration of central dopaminergic neurotransmission (Labandeira-García et al. 2014). The effect of ARBs was evaluated in drug induced animal schizophrenia models. Marchese et al. (2016) reported that losartan given intracerebroventricularly partially prevented the impairing effect of amphetamine in the inhibitory avoidance response of Wistar rats. In addition, losartan diminished amphetamineinduced hyperactivity in Wistar rats (Paz et al. 2014). Thus, it can be postulated that the antipsychotic effects of ARBs are linked with reduced brain KYNA concentration. To support this hypothesis, selective cyclooxygenase-2 (COX-2) inhibitors have also been proven to lower KYNA concentration in rat brain in vitro (Schwieler et al. 2006), as well as reduce amphetamine-induced behavioral changes in rats (El-Sayed El-Sisi et al. 2016). As a result, celecoxib is postulated as an adjunct therapy for patients with schizophrenia (Müller et al. 2010).
This study reports for the first time that ARBs inhibit KAT II activity and reduce KYNA production in cortical slices. The decrease of KYNA production in cortical slices can be explained by the inhibition of KAT II activity. Since the activity of KATs was investigated in partially purified enzymes, it can be concluded that the investigated ARBs, irbesartan, losartan, and telmisartan, are KAT inhibitors. This statement is further supported by our docking simulations which suggest that all studied ARBs bind to the KAT II active site.

Experimental data suggest that all analyzed ARBs can reach the central nervous system after peripheral administration (Zhuo et al. 1994; Culman et al. 1999; Kishi et al. 2012). Thus, it can be concluded that all examined ARBs can reach the central nervous system after systemic administration and affect KYNA production in the brain cortex.

This study has some limitations. Among the analyzed ARBs, only losartan potassium is water soluble, whereas irbesartan and telmisartan were dissolved in DMSO. Because of the limited solubility, the influence of telmisartan on KYNA production was examined up to $0.5 \mathrm{mM}$ concentration.

In conclusion, the obtained results demonstrate that ARBs decrease KYNA synthesis in the brain cortex in vitro by inhibition of KAT II. In addition, we suggest that each studied ARB may bind to the KAT II active site, inhibit enzyme activity, and subsequently block KYNA production. Further in vivo studies are needed to confirm the presented in vitro findings.

Acknowledgements This study was supported by a grant from the National Science Centre (NCN) PRELUDIUM 4 (no. UMO-2012/07/ $\mathrm{N} / \mathrm{NZ4} / 02088$ ). The NCN had no role in the study design, collection, analysis and interpretation of data, or in the writing of the article, and decision to submit the article for publication.

Author Contributions IZ and WAT designed the study on animals and wrote the experimental protocol. KT-D, AW, and KJ designed and performed the molecular docking and gene expression analysis. IZ, WAT and AW undertook literature searches and analyses. IZ and WAT performed the statistical analysis. IZ, WAT, and AW wrote the first draft of the manuscript. All authors contributed to and have approved the final manuscript.

\section{Compliance with Ethical Standards}

Conflict of Interest The authors declare that they have no conflict of interest.

Ethical Approval All applicable international, national, and institutional guidelines for the care and use of animals were followed. All procedures performed in the study involving animals were in accordance with the ethical standards of the institution at which the studies were conducted.

Open Access This article is distributed under the terms of the Creative Commons Attribution 4.0 International License (http:// creativecommons.org/licenses/by/4.0/), which permits unrestricted use, distribution, and reproduction in any medium, provided you give 
appropriate credit to the original author(s) and the source, provide a link to the Creative Commons license, and indicate if changes were made.

\section{References}

Araujo GC, Lopes OU, Campos RR (1999) Importance of glycinergic and glutamatergic synapses within the rostral ventrolateral medulla for blood pressure regulation in conscious rats. Hypertension 34: 752-755

Baltatu OC, Campos LA, Bader M (2011) Local renin-angiotensin system and the brain-a continuous quest for knowledge. Peptides 32: 1083-1086

Bar-Klein G, Cacheaux LP, Kamintsky L, Prager O, Weissberg I, Schoknecht K, Cheng P, Kim SY, Wood L, Heinemann U, Kaufer D, Friedman A (2014) Losartan prevents acquired epilepsy via TGF- $\beta$ signaling suppression. Ann Neurol 75:864-875

Baran H, Jellinger K, Deecke L (1999) Kynurenine metabolism in Alzheimer's disease. J Neural Transm (Vienna) 106:165-181

Beggiato S, Antonelli T, Tomasini MC, Tanganelli S, Fuxe K, Schwarcz R, Ferraro L (2013) Kynurenic acid, by targeting $\alpha 7$ nicotinic acetylcholine receptors, modulates extracellular GABA levels in the rat striatum in vivo. Eur J Neurosci 37:1470-1477

Colombari E, Sato MA, Cravo SL, Bergamaschi CT, Campos RR, Lopes OU (2001) Hypertension 38:549-554

Culman J, von Heyer C, Piepenburg B, Rascher W, Unger T (1999) Effects of systemic treatment with irbesartan and losartan on central responses to angiotensin II in conscious, normotensive rats. Eur J Pharmacol 367:255-265

Danielyan L, Klein R, Hanson LR, Buadze M, Schwab M, Gleiter CH, Frey WH (2010) Protective effects of intranasal losartan in the APP/ PS1 transgenic mouse model of Alzheimer disease. Rejuvenation Res 13:195-201

El-Sayed El-Sisi A, Sokkar SS, El-Sayed El-Sayad M, Sayed Ramadan E, Osman EY (2016) Celecoxib and omega-3 fatty acids alone and in combination with risperidone affect the behavior and brain biochemistry in amphetamine-induced model of schizophrenia. Biomed Pharmacother 82:425-431

ESH/ESC Task Force for the Management of Arterial Hypertension (2013) Practice guidelines for the management of arterial hypertension of the European Society of Hypertension (ESH) and the European Society of Cardiology (ESC) 2013. ESH/ESC Task Force for the Manag Arterial Hypertension J Hypertens 31:1925-1938

Fogari R, Mugellini A, Zoppi A, Derosa G, Pasotti C, Fogari E, Preti P (2003) Influence of losartan and atenolol on memory function in very elderly hypertensive patients. J Hum Hypertens 17:781-785

Ganten D, Minnich JL, Granger P, Hayduk K, Brecht HM, Barbeau A, Boucher R, Genest J (1971) Angiotensin-forming enzyme in brain tissue. Science 173:64-65

Guidetti P, Okuno E, Schwarcz R (1997) Characterization of rat brain kynurenine aminotransferases I and II. J Neurosci Res 50:457-65

Guillemin GJ, Smith DG, Kerr SJ, Smythe GA, Kapoor V, Armati PJ, Brew BJ (2000) Characterisation of kynurenine pathway metabolism in human astrocytes and implications in neuropathogenesis. Redox Rep 5:108-111

Hajjar I, Rodgers K (2013) Do angiotensin receptor blockers prevent Alzheimer's disease? Curr Opin Cardiol 28:417-425

Han Q, Robinson H, Li J (2008) Crystal structure of human kynurenine aminotransferase II. J Biol Chem 283:3567-3573

Intebi AD, Flaxman MS, Ganong WF, Deschepper CF (1990) Angiotensinogen production by rat astroglial cells in vitro and in vivo. Neuroscience 34:545-554
Ito S, Komatsu K, Tsukamoto K, Sved AF (2000) Excitatory amino acids in the rostral ventrolateral medulla support blood pressure in spontaneously hypertensive rats. Hypertension 35:413-417

Kapoor V, Kapoor R, Chalmers J (1994) Kynurenic acid, an endogenous glutamate antagonist, in SHR and WKY rats: possible role in central blood pressure regulation. Clin Exp Pharmacol Physiol 21:891-896

Kido H, Sasaki S, Oguni A, Harada S, Morimoto S, Takeda K, Nakagawa M (2004) Effects of angiotensin II type 1 receptor antagonist on pressor responses to pulsatile compression of the rostral ventrolateral medulla in rats. Hypertens Res 27:427-432

Kishi T, Hirooka Y, Sunagawa K (2012) Sympathoinhibition caused by orally administered telmisartan through inhibition of the $\mathrm{AT}_{1}$ receptor in the rostral ventrolateral medulla of hypertensive rats. Hypertens Res 35:940-946

Kondo K, Saruta T, Garcia R, Boucher R (1980) The effects of intracerebroventricular administration of tonin on water drinking and blood pressure in rats. Endocrinol Jpn 27:567-571

Kozak R, Campbell BM, Strick CA, Horner W, Hoffmann WE, Kiss T, Chapin DS, McGinnis D, Abbott AL, Roberts BM, Fonseca K, Guanowsky V, Young DA, Seymour PA, Dounay A, Hajos M, Williams GV, Castner SA (2014) Reduction of brain kynurenic acid improves cognitive function. J Neurosci 34:10592-10602

Kwok JB, Kapoor R, Gotoda T, Iwamoto Y, lizuka Y, Yamada N, Isaacs KE, Kushwaha VV, Church WB, Schofield PR, Kapoor V (2002) A missense mutation in kynurenine aminotransferase- 1 in spontaneously hypertensive rats. J Biol Chem 277:35779-35782

Labandeira-García JL, Garrido-Gil P, Rodriguez-Pallares J, Valenzuela R, Borrajo A, Rodríguez-Perez AI (2014) Brain renin-angiotensin system and dopaminergic cell vulnerability. Front Neuroanat 8:67

Liebig J (1853) Über Kynurensäure. Justus Liebigs Ann Chem 86:125126

Malkova L, Forcelli PA, Wellman LL, Dybdal D, Dubach MF, Gale K (2015) Blockade of glutamatergic transmission in perirhinal cortex impairs object recognition memory in macaques. J Neurosci 35: 5043-5050

Mankin LA (2016) Update in hypertension therapy. Med Clin North Am 100:665-693

Marchese NA, Artur de la Villarmois E, Basmadjian OM, Perez MF, Baiardi G, Bregonzio C (2016) Brain Angiotensin II AT1 receptors are involved in the acute and long-term amphetamine-induced neurocognitive alterations. Psychopharmacology 233:795-807

Mechaeil R, Gard P, Jackson A, Rusted J (2011) Cognitive enhancement following acute losartan in normotensive young adults. Psychopharmacology 217:51-60

Mills E, Minson J, Drolet G, Chalmers J (1990) Effect of intrathecal amino acid receptor antagonists on basal blood pressure and pressor responses to brainstem stimulation in normotensive and hypertensive rats. J Cardiovasc Pharmacol 15:877-883

Mizutani K, Sugimoto K, Okuda T, Katsuya T, Miyata T, Tanabe T, Higaki J, Ogihara T, Yamori Y, Tsujita Y, Tago N, Iwai N (2002) Kynureninase is a novel candidate gene for hypertension in spontaneously hypertensive rats. Hypertens Res 25:135-140

Müller N, Krause D, Dehning S, Musil R, Schennach-Wolff R, Obermeier M, Möller HJ, Klauss V, Schwarz MJ, Riedel M (2010) Celecoxib treatment in an early stage of schizophrenia: results of a randomized, double-blind, placebo-controlled trial of celecoxib augmentation of amisulpride treatment. Schizophr Res 121:118-124

Muñoz-Durango N, Fuentes CA, Castillo AE, González-Gómez LM, Vecchiola A, Fardella CE, Kalergis AM (2016) Role of the reninangiotensin-aldosterone system beyond blood pressure regulation: molecular and cellular mechanisms involved in end-organ damage during arterial hypertension. Int J Mol Sci pii:E797. doi:10.3390/ ijms17070797

Muratani H, Averill DB, Ferrario CM (1991) Effect of angiotensin II in ventrolateral medulla of spontaneously hypertensive rats. Am J Phys 260:R977-R984 
Muthuraman A, Kaur P (2016) Renin-angiotensin-aldosterone system: a current drug target for the management of neuropathic pain. Curr Drug Targets 17:178-195

Nematollahi A, Sun G, Jayawickrama GS, Church WB (2016) Kynurenine aminotransferase Isozyme inhibitors: a review. Int J Mol Sci pii E946. doi:10.3390/ijms17060946

Papadopoulos P, Tong XK, Imboden H, Hamel E (2017) Losartan improves cerebrovascular function in a mouse model of Alzheimer's disease with combined overproduction of amyloid- $\beta$ and transforming growth factor- $\beta 1$. J Cereb Blood Flow Metab 37: 1959-1970

Paz MC, Marchese NA, Stroppa MM, Gerez de Burgos NM, Imboden H, Baiardi G, Cancela LM, Bregonzio C (2014) Involvement of the brain renin-angiotensin system (RAS) in the neuroadaptive responses induced by amphetamine in a two-injection protocol. Behav Brain Res 272:314-323

Pereira MG, Becari C, Oliveira JA, Salgado MC, Garcia-Cairasco N, CostaNeto CM (2010) Inhibition of the renin-angiotensin system prevents seizures in a rat model of epilepsy. Clin Sci (Lond) 119:477-482

Plitman E, Iwata Y, Caravaggio F, Nakajima S, Chung JK, Gerretsen P, Kim J, Takeuchi H, Chakravarty MM, Remington G, Graff-Guerrero A (2017) Kynurenic acid in schizophrenia: a systematic review and meta-analysis. Schizophr Bull doi. doi:10.1093/schbul/sbw221

Sarganas G, Neuhauser HK (2016) Untreated, uncontrolled, and apparent resistant hypertension: results of the German Health Examination Survey 2008-2011. J Clin Hypertens (Greenwich) 18:1146-1154

Schwarcz R, Speciale C, French ED (1987) Hippocampal kynurenines as etiological factors in seizure disorders. Pol J Pharmacol Pharm 39: 485-494

Schwarcz R, Stone TW (2017) The kynurenine pathway and the brain: challenges, controversies and promises. Neuropharmacology 112: 237-247

Schwieler L, Erhardt S, Nilsson L, Linderholm K, Engberg G (2006) Effects of COX-1 and COX-2 inhibitors on the firing of rat midbrain dopaminergic neurons-possible involvement of endogenous kynurenic acid. Synapse 59:290-298

Stone TW, Stoy N, Darlington LG (2013) An expanding range of targets for kynurenine metabolites of tryptophan. Trends Pharmacol Sci 34: $136-143$
Sumners C, Tang W, Paulding W, Raizada MK (1994) Peptide receptors in astroglia: focus on angiotensin II and atrial natriuretic peptide. Glia 11:110-116

Sun H, Wu H, Yu X, Zhang G, Zhang R, Zhan S, Wang H, Bu N, Ma X, Li Y (2015) Angiotensin II and its receptor in activated microglia enhanced neuronal loss and cognitive impairment following pilocarpine-induced status epilepticus. Mol Cell Neurosci 65:58-67

Tagawa T, Fontes MA, Potts PD, Allen AM, Dampney RA (2000) The physiological role of AT1 receptors in the ventrolateral medulla. Braz J Med Biol Res 33:643-652

Tchekalarova JD, Ivanova NM, Pechlivanova DM, Atanasova D, Lazarov N, Kortenska L, Mitreva R, Lozanov V, Stoynev A (2014) Antiepileptogenic and neuroprotective effects of losartan in kainate model of temporal lobe epilepsy. Pharmacol Biochem Behav 127:27-36

Toney GM, Porter JP (1993) Functional roles of brain AT1 and AT2 receptors in the central angiotensin II pressor response in conscious young spontaneously hypertensive rats. Brain Res Dev Brain Res 71:193-199

Turski WA, Gramsbergen JB, Traitler H, Schwarcz R (1989) Rat brain slices produce and liberate kynurenic acid upon exposure to Lkynurenine. J Neurochem 52:1629-1636

Vieira AA, Colombari E, De Luca LA Jr, Colombari DS, De Paula PM, Menani JV (2010) Importance of angiotensinergic mechanisms for the pressor response to l-glutamate into the rostral ventrolateral medulla. Brain Res 1322:72-80

Wang J, Pang T, Hafko R, Benicky J, Sanchez-Lemus E, Saavedra JM (2014) Telmisartan ameliorates glutamate-induced neurotoxicity: roles of AT(1) receptor blockade and PPAR $\gamma$ activation. Neuropharmacology 79:249-261

Willette RN, Punnen-Grandy S, Krieger AJ, Sapru HN (1987) Differential regulation of regional vascular resistance by the rostral and caudal ventrolateral medulla in the rat. J Auton Nerv Syst 18: $143-151$

Zhuo J, Song K, Abdelrahman A, Mendelsohn FA (1994) Blockade by intravenous losartan of AT1 angiotensin II receptors in rat brain, kidney and adrenals demonstrated by in vitro autoradiography. Clin Exp Pharmacol Physiol 21:557-567 